\title{
PRECIPITATION IN SPRAY-FORMED IN 718
}

\author{
S. Azadian, Liu-Ying Wei \\ Division of Engineering Materials \\ Luleå University of Technology \\ SE 97187 Luleå, Sweden \\ F. Niklasson \\ Volvo Aero Corporation \\ SE 46181 Trollhättan, Sweden \\ R. Warren \\ Technology and Society \\ Malmö University \\ SE 20506 Malmö, Sweden
}

\begin{abstract}
The precipitation of the $\gamma^{\prime}, \gamma^{\prime \prime}$ and $\delta$ phases in a spray-formed version of IN 718 has been studied by hardness measurement and metallographic examination of samples subjected to solution treatment at $1025^{\circ} \mathrm{C}$ followed by isothermal treatments between 620 and $1010^{\circ} \mathrm{C}$ up to $100 \mathrm{~h}$. The precipitation processes were compared to those in a wrought (ring-rolled) version of the alloy subjected to the same heat treatments. Time-temperature-hardness diagrams for the two alloys were constructed. Small differences were observed between the two materials but these can at least partly be attributed to differences in composition. For the spray-cast material the $\delta$-phase solvus temperature was determined and the growth kinetics of the $\gamma^{\prime \prime}$ phase established
\end{abstract}




\section{Introduction}

A characteristic feature of the alloy IN 718 is that, after a conventional heat treatment, aside from carbides, it normally features three precipitate phases occurring simultaneously in its microstructure, namely $\gamma^{\prime}, \gamma^{\prime \prime}$ and $\delta$. The heat treatment of the alloy and consequently the nature of these phases have received considerable attention in reported studies (for example [1-6]. The main characteristics of the phases are summarized in Table I.

Conventionally, the alloy is used both in cast and wrought forms but recently the relatively new spray forming process has been applied to this alloy (7). This process is particularly advantageous for producing cylindrical products such as tubes and rings since for these fewer processing stages are required after spray forming than would be required using a conventional forging route. Moreover, the resulting material is presumed to be more homogeneous with respect to composition than cast and wrought forms. The aim of the present work was to characterize the precipitation processes in a spray-formed version of the alloy, comparing these with those in a wrought version. As a first stage in the work an objective was to generate a time-temperature-hardness diagram as a basis for subsequent microstructural and microanalytical evaluations.

Table I Common precipitate phases in IN 718

\begin{tabular}{lcccccc}
\hline Phase & Composition & $\begin{array}{c}\text { Crystal } \\
\text { structure }\end{array}$ & Habit wrt $\gamma$ matrix & $\begin{array}{c}\text { Particle } \\
\text { morphology }\end{array}$ & $\begin{array}{c}\text { Theoretical } \\
\text { maximum } \\
\text { amount** } \\
\text { (vol\%) }\end{array}$ & $\begin{array}{c}\text { Temperature } \\
\text { range ("C) }\end{array}$ \\
\hline$\gamma^{\prime}$ & $\mathrm{Ni}_{3}(\mathrm{Ti}, \mathrm{Al})^{*}$ & $\mathrm{FCC} ; \mathrm{Ll}_{2}$ & coherent & $\begin{array}{c}\text { spherical/ } \\
\text { cuboid: }<<1 \mu \mathrm{m}\end{array}$ & 8 & 650 to 850 \\
\hline$\gamma^{\prime \prime}$ & $\mathrm{Ni}_{3} \mathrm{Nb}^{*}$ & $\mathrm{BCT} ; \mathrm{DO}_{22}$ & $\begin{array}{c}(001)_{\gamma} / /(001)_{\gamma} \\
{[100]_{\gamma} / /<100>_{\gamma}}\end{array}$ & $\begin{array}{c}\text { disc up to } \\
1 \mu \text { m diameter }\end{array}$ & 13 & 620 to 900 \\
\hline$\delta$ & $\mathrm{Ni}_{3} \mathrm{Nb}^{*}$ & $\begin{array}{l}\text { orthorhombic; } \\
\text { DOa }\end{array}$ & $\begin{array}{c}(010)_{\delta} / /(11)_{\gamma} \\
{[100]_{\gamma} / /<110>_{\gamma}}\end{array}$ & $\begin{array}{c}\text { extensive } \\
\text { thin plates }\end{array}$ & 13 & 750 to $(930$ \\
\hline
\end{tabular}

${ }^{*} \gamma$ ' also contains some $\mathrm{Nb}: \gamma^{\prime \prime}$ and d also contain some Ti and Al.. **Assuming all available species taken up in the compound. ${ }^{* * *}$ Depends on $\mathrm{Nb}$ content (see text).

\section{Experimental}

\section{Materials - Including Microstructural State}

The spray-formed alloy was delivered by Sprayform Technologies International in the form of large, conical rings from 17 to $65 \mathrm{~mm}$ in thickness. Prior to delivery, the rings were hot isostatically pressed at $1024^{\circ} \mathrm{C} / 172 \mathrm{MPa} / 4 \mathrm{~h}$ followed by slow cooling. The wrought (ring-rolled) material in the as-delivered state had been mill-annealed at $982^{\circ} \mathrm{C} / 1 \mathrm{~h}$ followed by oil quenching. The compositions of the two alloys are given together with the standard specification in Table II.

The composition and microstructure of the spray-formed alloy was very uniform across the section of the ring. The difference in composition between the inside and the outside of the ring (measured by X-ray fluorescence) was negligible. Of most significance, the Nb content was 5.058 and $5.05 \mathrm{wt} \%$ at inside and outside respectively. The grains were equiaxed and the grain size, measured in terms of the mean intercept length, lay between 45 and $55 \mu \mathrm{m}$ across the 
thickest part of the section except adjacent to the substrate mandrel where it was $33 \mu \mathrm{m}$, due presumably to faster cooling at the start of the process. Similarly, the hardness (HV5) showed small variation, between 355 and 408 . The grain size of the ring-rolled material was similar to that of the spray-formed alloy but the microstructure was textured with elongated grains.

Table II Compositions of the Spray-Formed and Ring-Rolled IN 718 together with Specified Composition of the Alloy (wt $\%$ ).

\begin{tabular}{lccccccccccccc}
\hline Element & $\mathrm{Ni}$ & $\mathrm{Fe}$ & $\mathrm{Cr}$ & $\mathrm{Nb}$ & $\mathrm{Mo}$ & $\mathrm{Ti}$ & $\mathrm{Al}$ & $\mathrm{Co}$ & $\mathrm{C}$ & $\mathrm{Mn}$ & $\mathrm{Si}$ & $\begin{array}{c}\mathrm{Ti}+\mathrm{Al} \\
\mathrm{Ti}+\mathrm{Al} \\
\mathrm{Nb}\end{array}$ \\
\hline Spray & 53.24 & 17.9 & 18.8 & 5.06 & 3.04 & 0.93 & 0.44 & 0.36 & 0.03 & 0.05 & 0.08 & 1.37 & 0.27 \\
Wrought & 53.76 & 18.1 & 17.8 & 5.41 & 2.87 & 1.00 & 0.45 & 0.15 & 0.027 & 0.05 & 0.07 & 1.45 & 0.26 \\
Spec. (min.) & 50.00 & rem. & 17.00 & 4.75 & 2.80 & 0.65 & 0.2 & - & - & - & - & 0.85 & 0.17 \\
Spec. (max) & 55.00 & rem. & 21.00 & 5.5 & 3.30 & 1.15 & 0.8 & 1.00 & 0.08 & 0.35 & 0.35 & 1.95 & 0.35 \\
\hline
\end{tabular}

\section{$\underline{\text { Isothermal Heat Treatments }}$}

A series of isothermal heat treatments were carried out on both spray-formed and ring-rolled material at selected temperatures between $600^{\circ} \mathrm{C}$ and $1025^{\circ} \mathrm{C}$ for up to $100 \mathrm{~h}$. Preliminary isothermal treatments were carried out on the spray-formed alloy alone in order to establish a suitable solution treatment to be applied prior to the isothermal treatments. On this basis the solution treatment selected was $1025^{\circ} \mathrm{C} / 1 \mathrm{~h} /$ water quench; This was sufficient for the hardness (HV20) to fall from an as-received value of 340 to a steady value of 180 while the grain size increased to around $70 \mu \mathrm{m}$.

Heat treatments were carried out in air on small blocks $\approx 10 \times 10 \times 15 \mathrm{~mm}$ cut from the supplied rings. In most cases the spray-formed and ring-rolled samples were heat treated together. The furnace was a box furnace $(25 \times 30 \times 30 \mathrm{~cm})$ with programmable temperature control run via a type $\mathrm{Pt} / \mathrm{Rh}$ thermocouple. The specimen temperature was measured with a type $\mathrm{K}$ chromel/alumel thermocouple welded to the sample surface. Errors in temperature measurement are estimated to be within $\pm 5^{\circ} \mathrm{C}$. Following heat treatment, all samples were water quenched unless otherwise stated.

The heat treatment was started by placing the samples in the furnace preheated to the treatment temperature. The time taken by the samples to reach the temperature varied between 3 and 6.5 minutes depending on the temperature as indicated in Table III. It should be noted that since the heat treatment time was started nominally from the instant that the set temperature was reached, the precipitation process could begin already before zero time.

Table III Heating Times to Reach Heat Treatment Temperatures.

\begin{tabular}{ccccccccccc}
\hline Temperature $\left({ }^{\circ} \mathrm{C}\right)$ & 620 & 650 & 700 & 750 & 800 & 850 & 900 & 950 & 1000 & 1025 \\
\hline Heating time $(\mathrm{min})$ & 3.35 & 3.42 & 3.52 & 4.10 & 4.36 & 4.40 & 4.50 & 5.00 & 5.30 & 6.5 \\
\hline
\end{tabular}


Heat treated specimens were studied using optical microscopy, scanning electron microscopy (SEM) and transmission electron microscopy (TEM). SEM was suitable for observation of grain structure and advanced stages of precipitation while TEM was necessary for detailed examination of precipitate structure and for characterisation of the early stages of precipitation. Specimens investigated with TEM were spray-formed treated $620^{\circ} \mathrm{C} / 24 \mathrm{~h}, 700^{\circ} \mathrm{C} / 24 \mathrm{~h}$, $750^{\circ} \mathrm{C} / 24 \mathrm{~h}, 800^{\circ} \mathrm{C} / 0 \mathrm{~h}, 875^{\circ} \mathrm{C} / 6 \mathrm{~h}$.

SEM samples were prepared in one of two ways. The first method was a conventional preparation involving cutting,, mounting in mounting plastic, preparation by programmed conventional grinding and mechanical polishing and chemically etching. A variety of etchants were used depending on the microstructural features of interest. The alternative method, applied to samples from the isothermal heat treatment studies, involved cutting $1 \mathrm{~mm}$ thick slices from the sample in a water-cooled cutting machine. These were then mechanically ground, electropolished and finally etched electrolytically. The electropolishing was performed in a Streuers Tenupol-3 twin-jet unit in a solution of $20 \% \mathrm{H}_{2} \mathrm{SO}_{4}$ in methanol at $30 \mathrm{~V}, 2-4 \mathrm{~A}, 0^{\circ} \mathrm{C}, 20$ 25 seconds. The electrolytic etch was a solution of $170 \mathrm{cc} \mathrm{H}_{3} \mathrm{PO}_{4}: 10 \mathrm{cc} \mathrm{H}_{2} \mathrm{SO}_{4}: 15 \mathrm{~g} \mathrm{Cr} \mathrm{O}_{3}$ at $5 \mathrm{~V}$, $1.5 \mathrm{~A}, 0^{\circ} \mathrm{C}, 10-15$ seconds.

Thin foils for TEM were prepared by cutting out $1 \mathrm{~mm}$ slices from the sample, mechanical grinding down to $80 \mu \mathrm{m}$ thickness followed by electropolishing to suitable thickness for electron transparency in the electropolishing equipment mentioned above. In this case the solution was $10 \% \mathrm{HClO}_{4}$ in methanol at $25 \mathrm{~V}, 0.5 \mathrm{~A},-20$ to $-25^{\circ} \mathrm{C}, 20-25$ seconds.

The SEM studies were made in a Philips XL 30 (Link- ISIS EDX system) and a CamScan series 4 (Link-eXl system) while the TEM investigations were carried out with a Jeol 2000 EX, $200 \mathrm{KeV}$ (Link- 10000 XEDS system).

Hardness was measured on samples mounted in plastic in a macrohardness tester using a Vickers diamond indenter at loads between 5 and $20 \mathrm{kp}$. The average of three indentations was taken. For a given sample these did not vary by more than 10 hardness numbers.

\section{Results and Discussion}

\section{Time-Temperature-Hardness Diagrams}

The hardening responses of the two alloys are shown as TTH diagrams in Figures 1 and 2 and as hardening curves in Figure 3. In general, the results are consistent with earlier studies of wrought IN718 (e.g.[2]) and indicate optimum hardening (i.e. hardness around 450HV within reasonable ageing times) in the range $650-750^{\circ} \mathrm{C}$. Differences between the ring-rolled and spray-formed materials were relatively small. The spray-formed material showed a slightly faster hardening response during the earlier stages of hardening. Both alloys exhibit very fast hardening in the range $800-850^{\circ} \mathrm{C}$ such that a significant hardening is seen already at zero isothermal ageing time, implying that precipitation had already occurred during heating. At $850^{\circ} \mathrm{C}$, the spray-formed alloy appeared to show two hardening peaks, one at zero time and one at 10 minutes. It is also of interest to note that at $1025^{\circ} \mathrm{C}$ the wrought material retained a relatively high hardness for the first 10 minutes of aging, an effect that was absent in the sprayformed material. 
Spray- formed IN 718

Treatment : Solution annealed

TTH diagram!

at $1025 \ldots \mathrm{C}$ for $1 \mathrm{~h}$

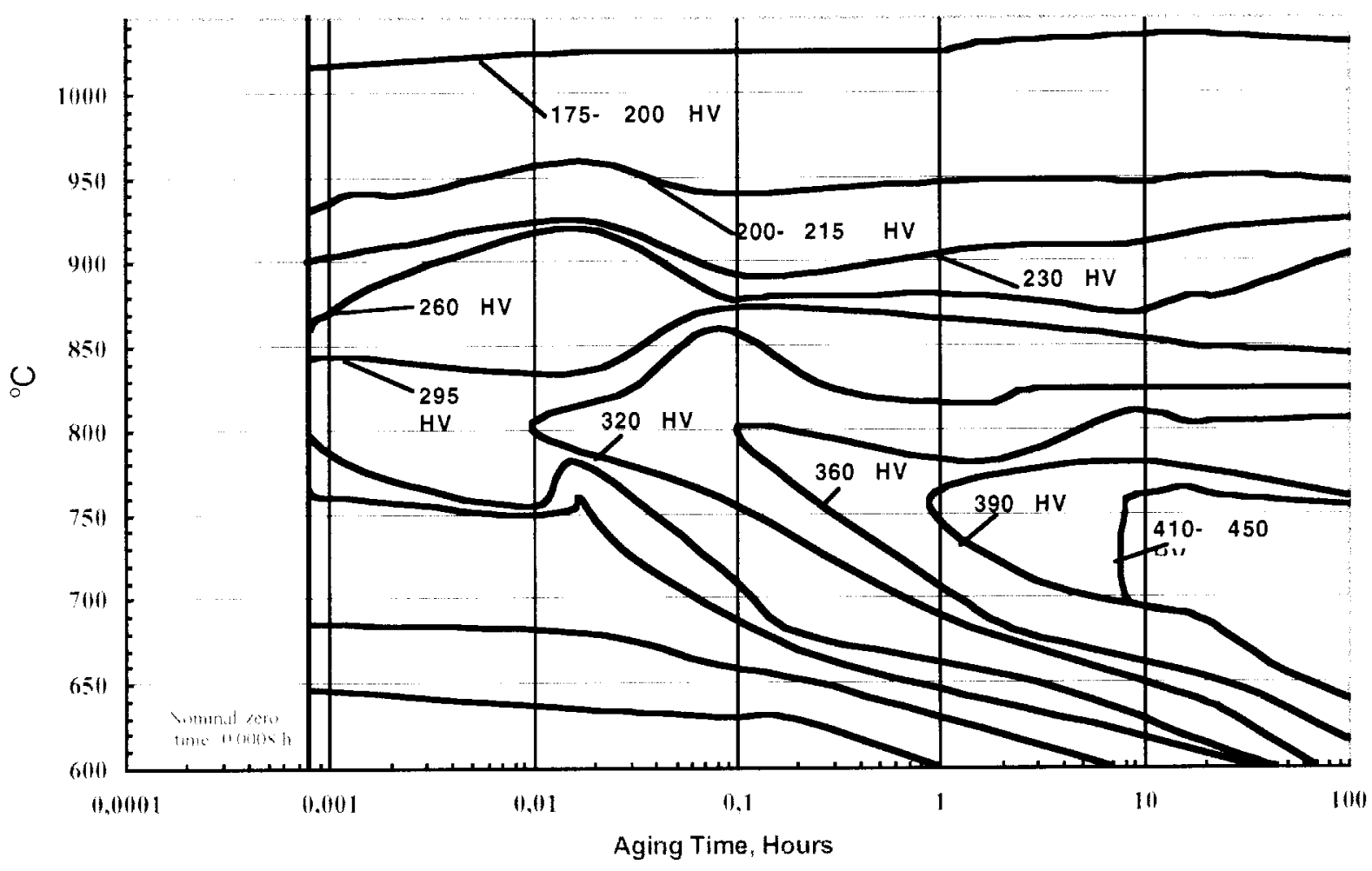

Figure 1: Time-temperature-hardness diagram for spray-formed IN 718.

Wrought IN 718

Treatment : Solution annealed

at $1025 \ldots$ for $1 \mathrm{~h}$

TTT diagram

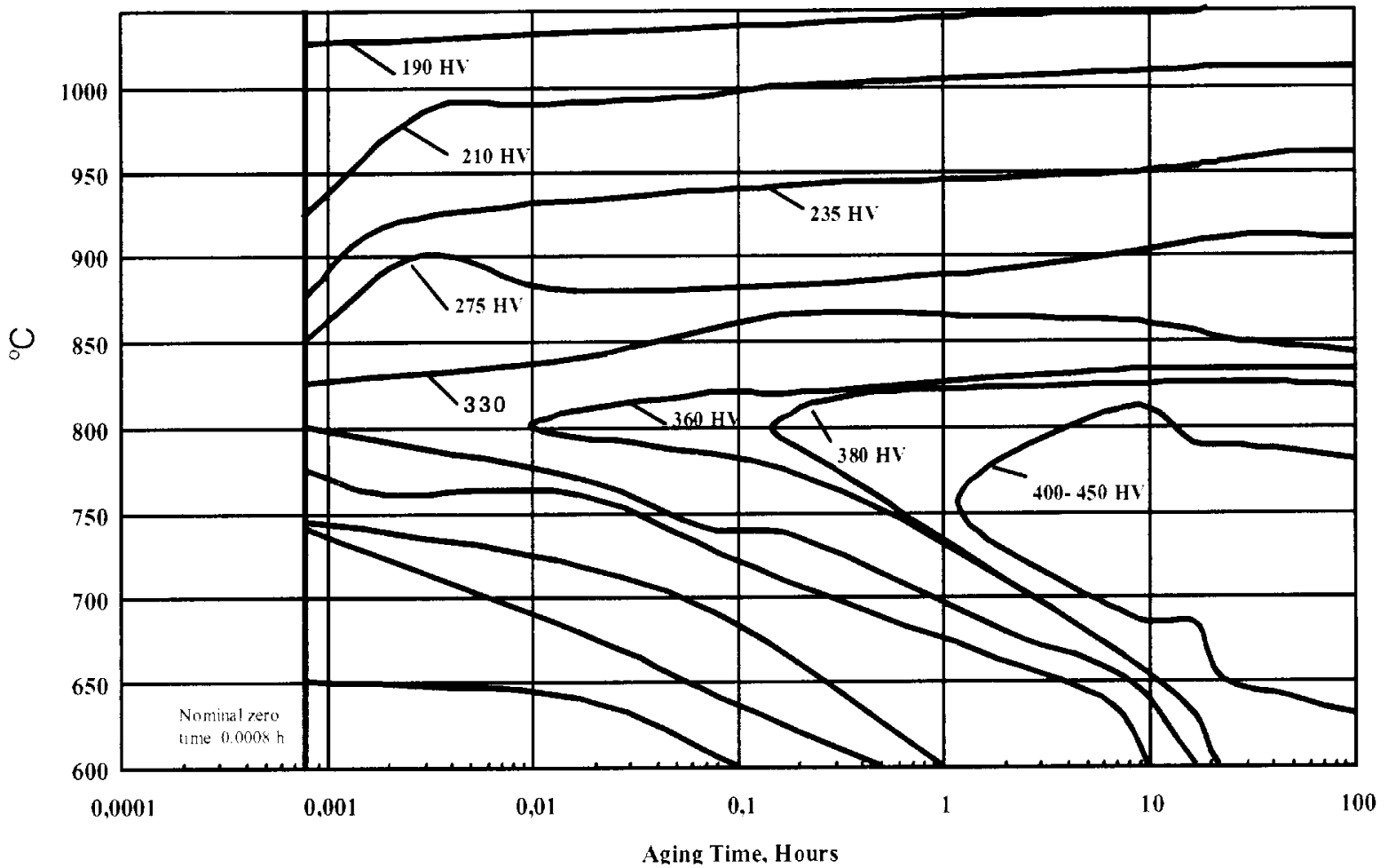

Figure 2: Time-temperature-hardness diagram for ring-rolled IN 718. 


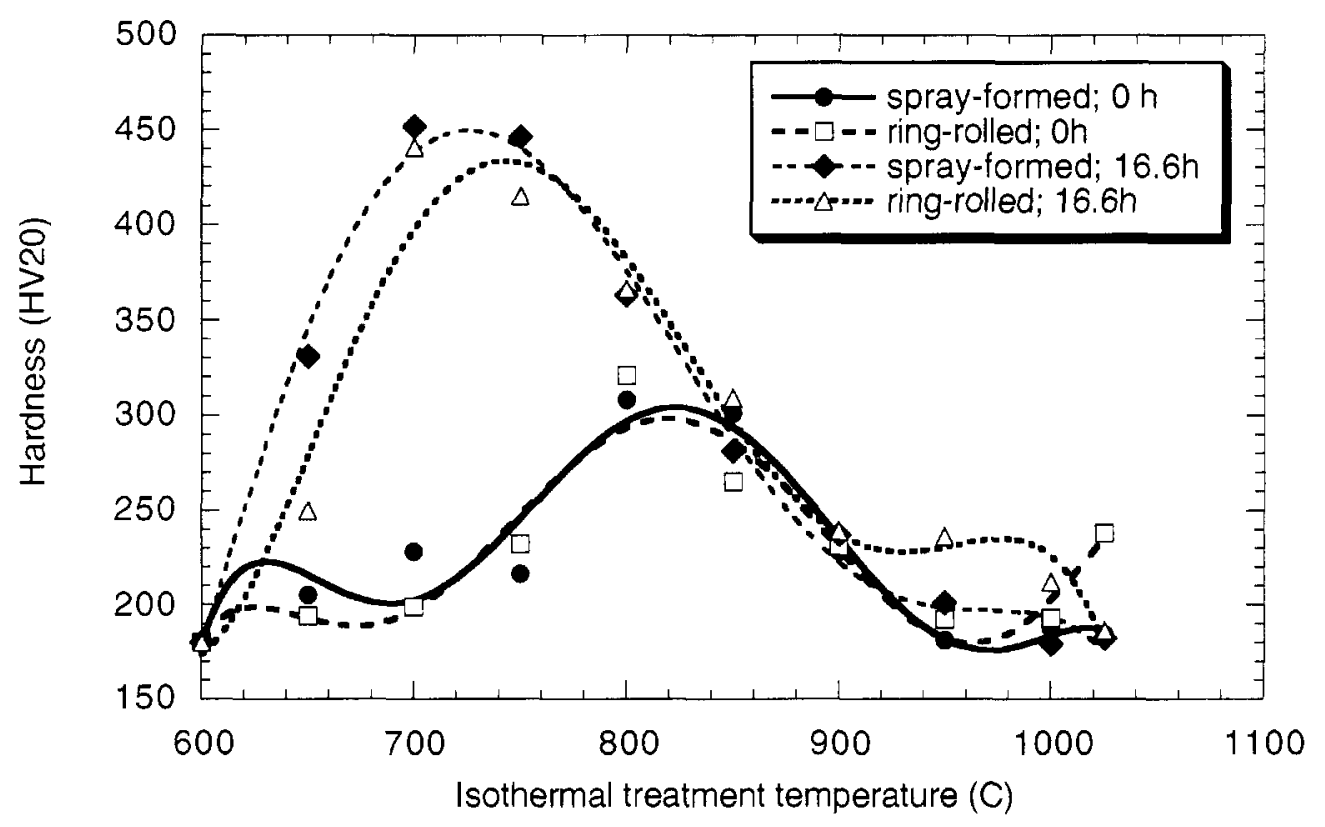

Figure 3: Hardness response of spray-formed and ring-rolled IN 718 as a function of temperature for isothermal aging times of 0 and $16.6 \mathrm{~h}$ where $0 \mathrm{~h}$ implies heating to the aging temperature followed by immediate quench.

The small differences in the two alloys can be explained in terms of differences in the details of precipitation which in turn can be explained -at least partly-by differences in the compositions, in particular the $\mathrm{Nb}$, Ti and $\mathrm{Al}$ contents (see next section).

\section{Microstructure}

The precipitation characteristics of wrought IN 718 have been reported extensively in earlier literature [e.g. 1-6] and the results of this work are largely consistent with these earlier studies. The main characteristics of the three precipitates are summarised in Table I.

Solution treatment and $\delta$-phase. Treatment of the spray formed alloy at 1025 and $1010^{\circ} \mathrm{C}$ led to no $\delta$ phase in the microstructure whereas at $1000^{\circ} \mathrm{C}$ small traces were found confirming that for this $\mathrm{Nb}$ content $(5.06 \%)$ the solvus lies between $1000^{\circ} \mathrm{C}$ and $1010^{\circ} \mathrm{C}$. At $1010^{\circ} \mathrm{C}$ and $1025^{\circ} \mathrm{C}$, the microstructure contained a small fraction of carbide precipitates gathered mainly at grain boundaries. The fraction of these increased slightly during heat treatment at these temperatures, e.g from $\approx 0.5$ to $1.5 \mathrm{vol} \%$ during $2 \mathrm{~h}$ at $1010^{\circ} \mathrm{C}$. At the same time they coarsened from about $\approx 0.5$ to $2 \mu \mathrm{m}$ in diameter. The increased carbide content may account for the small increase in hardness observed.

The ring-rolled alloy contained a significant amount of $\delta$ phase in the as-received state in the form of globular $\delta$ formed during the earlier processing. In contrast to the spray-formed alloy, a trace still remained after the $1025^{\circ} \mathrm{C} / 1 \mathrm{~h}$ solution treatment indicating that the solvus lay close to this temperature, consistent with the higher $\mathrm{Nb}$ content in the wrought alloy. 
In the spray-formed material the $\delta$ phase precipitated at $1000^{\circ} \mathrm{C}$ and below. The precipitation began at grain boundaries both within the boundary and as very thin platelets growing from the boundaries (Figure 4). With increasing time the platelets grow longer into the grain interiors and eventually seem to trigger new platelets within the grain. The highest growth rate was observed at $930^{\circ} \mathrm{C}$ being slightly faster than at 950 and $954^{\circ} \mathrm{C}$ (the temperature commonly selected as solution temperature prior to aging of this alloy[8]); thus the nose of the TTT-curve is assumed to be around this temperature. At $900^{\circ} \mathrm{C}$ and below, $\gamma^{\prime \prime}$ also precipitated within the grains (see below) and $\delta$ phase was observed to nucleate within $\gamma$ " particles (Figure 5). Reliable quantitative measurements of the amounts of $\delta$ precipitates have not been made at the time of writing but up to about $10 \mathrm{vol} \%$ was observed at the longer treatment times.

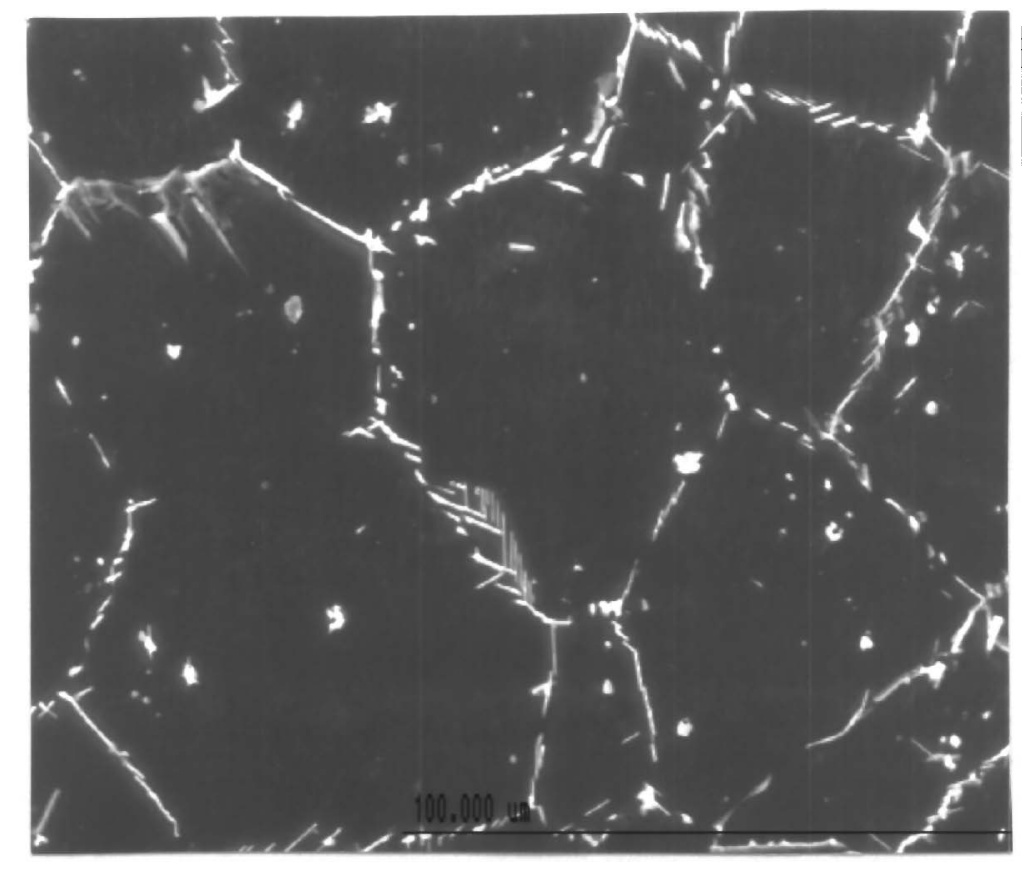

Figure 4: SEM micrograph showing $\delta$-phase precipitation in spray-formed IN 718 after isothermal treatment of $950^{\circ} \mathrm{C} / 100 \mathrm{~min}$

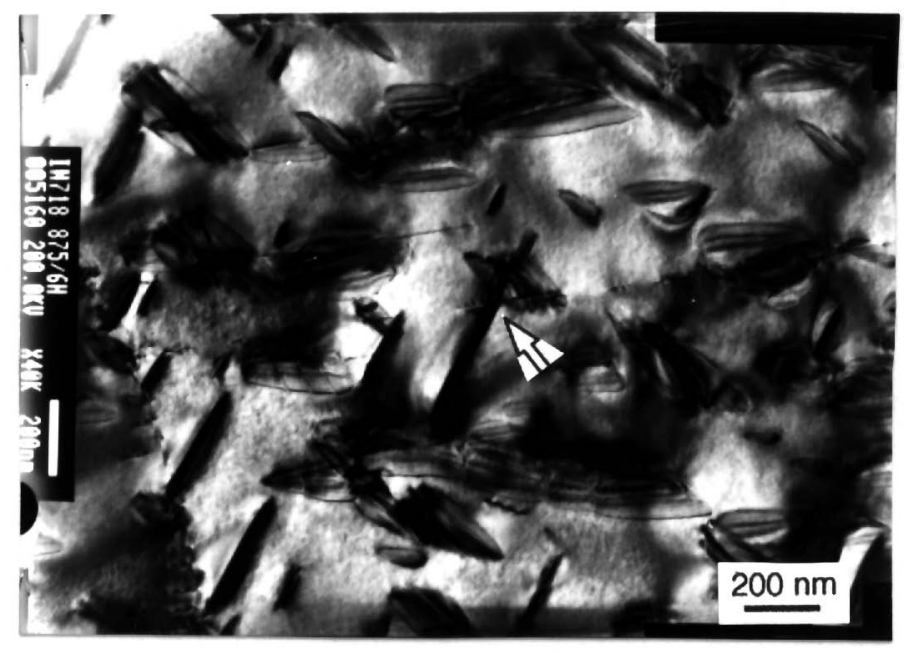

Figure 5: TEM micrograph showing early stage of $\delta$-platelet formation within $\gamma^{\prime \prime}$ precipitates in spray-formed IN 718 after aging at $875^{\circ} \mathrm{C} / 6 \mathrm{~h}$ 
The morphology and rates of $\delta$ precipitation were similar in the wrought alloy to those in the spray-formed alloy. However, in the former the fraction of precipitate attained at a given temperature was higher, given sufficient time. In particular, in contrast to the spray-formed alloy, significant precipitation occurred in the wrought material at $1000^{\circ} \mathrm{C}$. These differences, also indicated by the hardness evolution in the two alloys at 950 and $1000^{\circ} \mathrm{C}$, are consistent with the higher $\mathrm{Nb}$ content of the ring-rolled alloy leading to the higher solvus temperature.

In the spray-formed alloy, the first traces of $\delta$ precipitation were detected after $24 \mathrm{~h}$ at $750^{\circ} \mathrm{C}$ and between 10 and 100 minutes at $800^{\circ} \mathrm{C}$ which is somewhat earlier than indicated by the results of Brooks and Bridges [3] but consistent with other studies (see e.g. [1]).

$\gamma^{\prime}$ and $\gamma^{\prime}$ precipitation. Both the $\gamma^{\prime}$ and $\gamma^{\prime}$ 'precipitated homogeneously within the grains. The $\gamma^{\prime}$ was relatively easy to detect because of it characteristic disc shape. Since at more advanced stages of growth the discs grew to several hundred $\mathrm{nm}$ in diameter they could be fairly readily observed by SEM (Figure 6). The $\gamma$ ' phase formed as small spheres and was difficult to distinguish in structures containing $\gamma^{\prime \prime}$. The distinction could be made using diffraction techniques such as dark field imaging in TEM but so far it has not been possible to make quantitative estimates of fractions. However, in Figure 6, the $\gamma^{\prime}$ phase can be clearly recognised in zones around $\delta$-phase plates; the $\delta$ phase removes $\mathrm{Nb}$ from these zones but not the $\mathrm{Ti}$ and $\mathrm{Al}$ required for $\gamma^{\prime}$ formation. Similar micrographs taken at $900^{\circ} \mathrm{C}$ show little or no $\gamma^{\prime}$ in the denuded zones. Similarly, no $\gamma^{\prime}$ could be detected using electron diffraction in TEM on a sprayformed sample treated $6 \mathrm{~h}$ at $875^{\circ} \mathrm{C}$ indicating that the solvus for $\gamma^{\prime}$ lies between $850^{\circ} \mathrm{C}$ and this temperature.

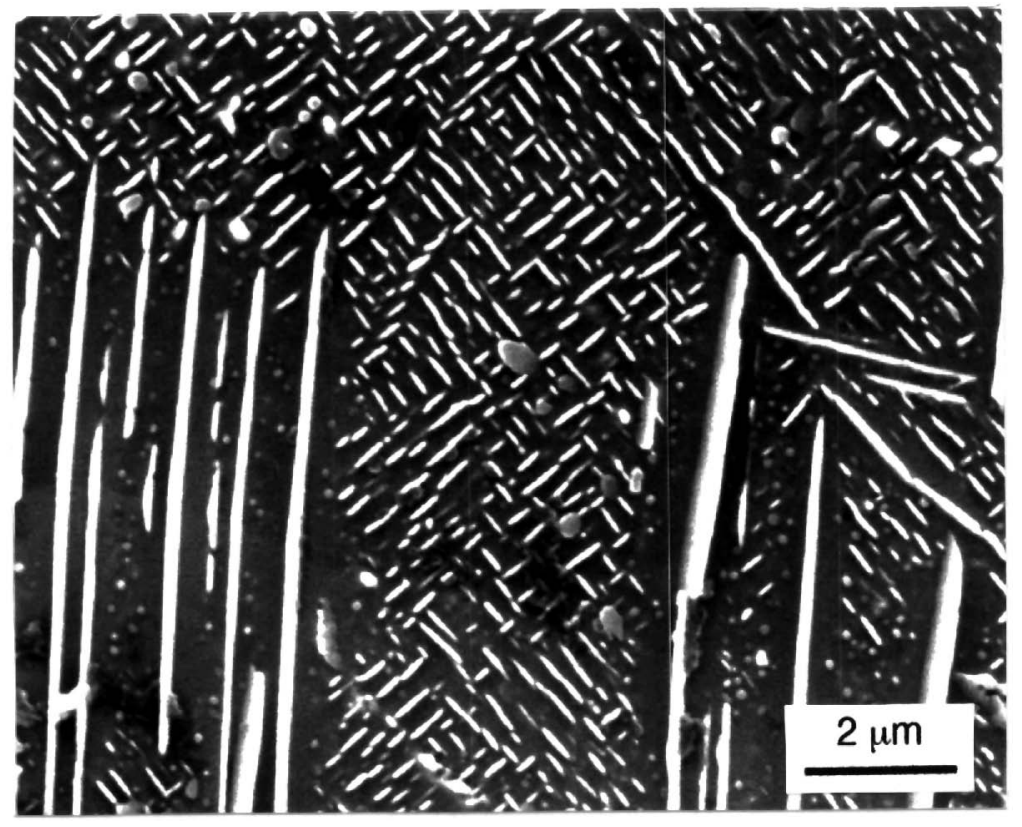

Figure 6: SEM microgarph showing $\delta$-phase plates, $\gamma^{\prime}$ discs and $\gamma^{\prime}$ spheroids in IN 718 treated isothermally at $850^{\circ} \mathrm{C} / 24 \mathrm{~h}$

In general, the $\gamma^{\prime}$ and $\gamma^{\prime \prime}$ nucleate and grow separately. However, at $750^{\circ} \mathrm{C}$, the two precipitates grow together as hemispherical particles in which the $\gamma^{\prime \prime}$ disc grows on the flat face of the $\gamma^{\prime}$ hemisphere (Figure 7). This phenomenon has been reported by Cozar and Pineau [5] and 
Sundararaman et al. [6]. A plausible explanation is that the phase having the greatest difficulty to nucleate at this temperature is able to nucleate heterogenously on the other.

The precipitation of the two phases begins at about $620^{\circ} \mathrm{C}$. After $24 \mathrm{~h}$ at this temperature the precipitates could not been distinguished individually in TEM but the TEM image exhibited a mottled appearance indicating high coherency between precipitates and matrix. The diffraction pattern indicated a significant amount of both $\gamma^{\prime}$ and $\gamma^{\prime}$. At $800^{\circ} \mathrm{C} / 0 \mathrm{~h}$ where the peak in zero time hardness occurs (Figure 3), the precipitate appeared to be predominantly $\gamma$ " with a diameter of about $5 \mathrm{~nm}$ and fully coherent with the matrix. This coherency could explain the double hardening peak at observed in the spray-formed alloy at $850^{\circ} \mathrm{C}$. With increasing time the precipitate would become semi-coherent, leading to a softening, followed by hardening as the volume fraction subsequently increased.

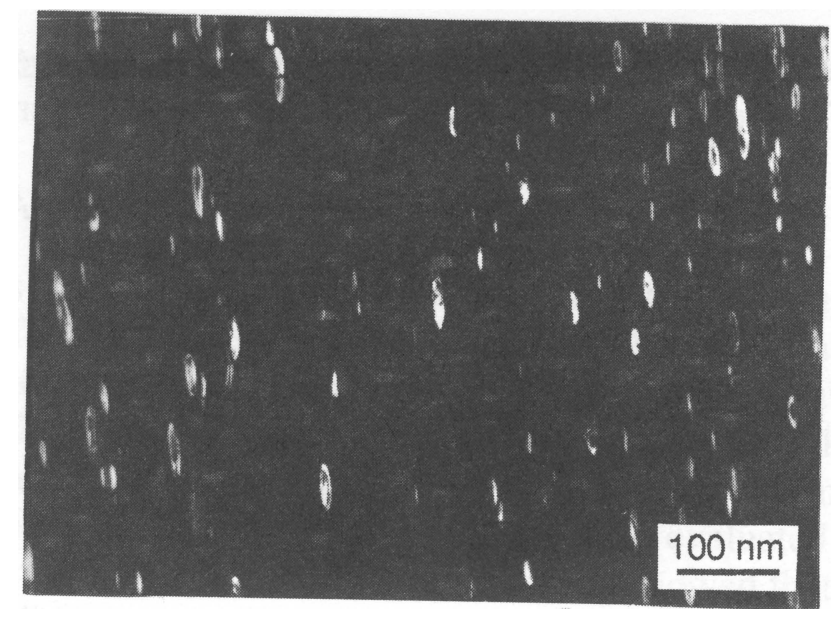

Figure 7: TEM dark-field micrograph showing $\gamma^{\prime}$ discs growing on the faces of $\gamma^{\prime}$ hemispheres in spray-formed IN 718 isothermally treated at $750^{\circ} \mathrm{C} / 24 \mathrm{~h}$.

At $700^{\circ} \mathrm{C}$ and above the particles became distinguishable. Moreover, the size of the $\gamma^{\prime \prime}$ particles could be measured in terms of the disc diameter which attained values up to around $1 \mu \mathrm{m}$ at longer times in the higher temperature range. The isothermal growth was consistent with cuberoot time dependence. Moreover, the growth rate constants were in good agreement with the Arrhenius equation as a function of temperature, with an estimated "activation energy" for the growth process of $43 \mathrm{kcal} / \mathrm{mol}$ which is reasonable for a diffusion controlled process. The growth rates in the spray-formed and ring-rolled alloys were very similar.

\section{Acknowledgments}

The authors would like to thank the Swedish National Energy Administration (STEM) for partial funding of this work.

\section{References}

1. E.E. Brown and D.R. Muzyka, D.R., "Nickel-Iron Alloys," Superalloys Il, ed. C.T. Sims, N.S. Stoloff, and W.C. Hagel (New York, NY: John Wiley \& Sons, New York, 1987), 165-188. 
2. H.L. Eiselstein, "Metallurgy of a Columbium-Hardened Nickel-Chromium-Iron alloy," ASTM STP No. 369, (1965), 62-79.

3. J.W. Brooks and P. Bridges, "Metallurgical Stability of Inconel Alloy 718," Superalloys 1988 (Warrendale, PA: The Metallurgical Society, 1988), 33-42.

4. J.P. Coller, S.H. Wong and J.K. Tien, "The Effect of Varying Al, Ti, and Nb Content on the Phase Stability of Inconel 718," Met. Ttrans. A, 19A (1988), 1657-1666.

5. R. Cozar, and A. Pineau, "Morphology of $\gamma$ ' and $\gamma$ " Precipitates and Thermal Stability of Inconel 718 Type Alloys," Met. Trans., 4 (1973), 47-59.

6. M. Sundararaman, P. Mukhopadhyay, and S. Banerjee., "Some Aspects of the Precipitation of Metastable Intermetallic Phases in Inconel 718," Met. Trans. A,.23A (1992), 2015-2028.

7. N. Paton et al. "Spraycast-X Inconel 718 Processing Benefits," Superalloys 718, 625, 706 and Various Derivatives (Warrendale, PA: The Minerals, Metals \& Materials Society, 1997).

8. "Aerospace Material Specification AMS 5662K" (Warrendale, PA: SAE International, 1998). 